Rev. Ter. Ocup. Univ. São Paulo, v. 17, n. 3, p. 129-136, set./dez., 2006.

\title{
Sofrimento psíquico e envelhecimento no trabalho: um estudo com agentes de trânsito*
}

\author{
Psychic suffering and ageing at work: \\ a study with transit agents
}

\author{
Selma Lancman¹, Laerte Idal Sznelwar², Tatiana Andrade Jardim³
}

\begin{abstract}
LANCMAN, S.; SZNELWAR, L. I.; JARDIM, T. A. Sofrimento psíquico e envelhecimento no trabalho: um estudo com agentes de trânsito. Rev. Ter. Ocup. Univ. São Paulo, v. 17, n. 3, p. 129-136, set./dez., 2006.

RESUMO: A partir de um estudo com agentes de trânsito procuramos discutir as relações entre trabalho e saúde mental e suas implicações nos processos de envelhecimento. Procuramos compreender os processos geradores de sofrimento psíquico, seus reflexos na vida e na saúde, no desenvolvimento do trabalho e de suas relações. A partir dos princípios teóricos e metodológicos da psicodinâmica do trabalho foram propostos grupos de reflexão com agentes de trânsito que têm a rua como local de trabalho. A partir de uma demanda relacionada com o aparecimento de sinais de deterioração da saúde desses trabalhadores e de absenteísmo crescente, questionamos se o sofrimento psíquico vivenciado ao longo dos anos diminui a capacidade de lidar com os constrangimentos impostos pelo trabalho ocasionando inclusive a perda da tolerância para lidar com o público, fato que poderia aumentar a vulnerabilidade às agressões e aos conflitos.
\end{abstract}

DESCRITORES: Saúde mental. Trabalho/psicologia. Estresse psicológico. Ambiente de trabalho/efeitos adversos. Envelhecimento.

\footnotetext{
* Trabalho realizado no Departamento de Estacionamento Rotativo da Companhia de Engenharia de Tráfego da cidade de São Paulo. Subvencionamento: CNPq, Edital Universal. Processo no 473880-2003-2.

Prof ${ }^{a}$ Livre Docente do curso de Terapia Ocupacional do Departamento de Fisioterapia, Fonoaudiologia e Terapia Ocupacional da Faculdade de Medicina da Universidade de São Paulo.

${ }_{3}^{2}$ Prof $^{\circ}$. Dr. do curso de Engenharia de Produção do Departamento de Engenharia de Produção da Escola Politécnica da Universidade de São Paulo.

3 Mestranda do Programa de Ciências da Reabilitação / Departamento de Fisioterapia, Fonoaudiologia e Terapia Ocupacional da Faculdade de Medicina da Universidade de São Paulo.

Endereço para correspondência: Departamento de Fisioterapia, Fonoaudiologia e Terapia Ocupacional da FMUSP. Rua Cipotanea, 51. CEP 05360-000. São Paulo, SP. e-mail: lancman@usp.br
} 


\section{INTRODUÇÃO}

$\mathrm{N}$ os últimos anos, com a introdução de novas tecnologias, a aceleração do ritmo do trabalho e novas formas de organização do modo de produção, as relações de trabalho têm sofrido intensas mudanças. Essas mudanças criam um processo de precarização, ou seja: o emprego, a carreira profissional linear e progressiva onde os trabalhadores permaneciam no trabalho até a aposentadoria, os direitos trabalhistas e a proteção à saúde cederam espaço à novas relações de trabalho, mais instáveis e precárias (GÓMEZ; THEDIMCOSTA, 1999; SENNETT, 1999).

Tradicionalmente, o modo de produção é pensado para um trabalhador imutável ao longo do tempo, que possua ao mesmo tempo experiência e capacidade para aprender rapidamente as novas regras da produção e que não envelheça e não perca a capacidade para o trabalho. $\mathrm{O}$ ciclo de permanência no trabalho tem se tornado cada vez mais curto e processos como "renovação da força de trabalho" são aceitos como parte das modernizações tecnológicas. A experiência no trabalho e o saber-fazer adquiridos com a idade passam a ser desvalorizados como contribuição ao processo de produção acelerando a exclusão dos trabalhadores mais idosos (VOLKOFF; LAVILLE, 1998). Esses autores alertam que o envelhecimento não significa necessariamente a diminuição da "capacidade para o trabalho" e que o declínio eventual de certas habilidades, relacionadas ao aumento da idade, não são generalizáveis, marcantes, nem uniformes, podendo ser aceleradas ou retardadas a depender das condições de trabalho, dos indivíduos e, sobretudo, dos tipos de desgaste aos quais o trabalhador é submetido.

O processo de envelhecimento no trabalho se inscreve em três dimensões - a história individual, a evolução das gerações e a evolução do trabalho e da sociedade (LAVILLE; VOLKOFF, 2004). Esse processo ocorre de duas maneiras diferentes: o envelhecimento pelo trabalho, onde o trabalho e as condições de execução agem sobre o processo de envelhecimento, sobre a diminuição de certas capacidades e sobre a modalidade de construção da experiência e o envelhecimento em relação ao trabalho, onde as transformações sofridas pelos indivíduos facilitam ou dificultam as atividades dos trabalhadores (sejam elas, negativas - menor tolerância à fadiga, diminuição do desempenho, desqualificação profissional; ou positivas reorganização eficiente da maneira de trabalhar, mobilidade ascendente, etc.).

Os conceitos de envelhecimento no trabalho, sofrimento patogênico e fadiga crônica não podem ser confundidos. Alguns sinais que são, na maioria das vezes, atribuídos ao envelhecimento dos trabalhadores, são relacionados a aspectos do conteúdo e da organização das tarefas. Alguns estudiosos observaram uma diminuição estatisticamente significativa da frequiência de fadiga e desgaste quando o trabalhador tem possibilidades de desenvolver sua inteligência, meios de fazer um trabalho de boa qualidade, margem de manobra e possibilidades de escolher a maneira de construir suas ações. Esta fadiga aumenta significativamente quando o trabalhador não tem poder e governabilidade sobre aquilo que faz, é submetido a horários atípicos, a tarefas repetitivas sob constrangimento de tempo e/ou tem pouca ou nenhuma possibilidade de trilhar sua carreira profissional. Esses autores concluem que as situações relacionadas aos aspectos subjetivos vivenciados no trabalho são a maior causa de sofrimento e que estes aspectos são mais significativos do que a idade ou o tempo de trabalho (BERTIN; DERRIENNIC, 2001; VEZINA et al., 2001).

Com o avançar da idade as pessoas se tornam mais experientes, o que pode auxiliar na construção de um novo equilíbrio e a superação do declínio de certas capacidades. A depender da tarefa e dos limites impostos pela organização, esta atividade pode acentuar o processo de declínio ou enriquecer a experiência e aumentar a competência (LAVILLE; VOLKOFF, 2004).

O Brasil começa a conviver com o aumento da expectativa de vida aumentando, assim, a inserção no trabalho de pessoas mais idosas. As últimas reformas da previdência, ao aumentarem a idade mínima para a aposentadoria induziram, de um lado, a permanência de trabalhadores por mais tempo no mercado de trabalho e de outro, a permanência ou retorno a uma atividade remunerada de pessoas mais idosas devido à necessidade de completar a renda. Cria-se um paradoxo, de um lado, a necessidade de trabalhar mais tempo para alcançar uma aposentadoria e, de outro, um mercado de trabalho cada vez mais desestruturado, incapaz de proporcionar empregos formais e de longa duração para a maioria dos ocupados (SALVADOR; BOSCHETTI, 2003).

Neste artigo, estamos focando o trabalho daqueles que permanecem no setor formal, no setor de serviços públicos e que por possuírem vínculos de trabalho estáveis trabalham até completar o período necessário para a aposentadoria, e que, portanto, vivenciam o processo de envelhecimento no trabalho.

\section{Trabalho no setor público}

O setor público tem sofrido mudanças significativas 
na sua organização, tais como, privatizações de empresas públicas seguidas de demissões, transferência para o setor privado através de ações de terceirização e externalização de setores da produção, enxugamento de efetivos e implantação de metas de produtividade. Em muitas situações, essas mudanças são acompanhadas por deterioração das condições de trabalho, sobrecarga para os que permanecem, falta de inovação tecnológica para suprir o aumento na demanda de serviço, deterioração da imagem do funcionário público e responsabilização dos mesmos pelas inoperâncias dos serviços e pelas crises das instituições públicas. Entre as causas de precarização dos serviços estariam as mudanças organizacionais que não levam em conta características da população trabalhadora, entre elas, o envelhecimento em relação ao trabalho.

Os serviços públicos têm adotado formas diversas de enxugamento dos seus quadros que vão desde programas de demissões voluntárias até a não reposição de trabalhadores afastados por adoecimentos ou aposentadorias. Apesar de terem relações menos instáveis de trabalho (menor exposição ao risco de demissão sumária) os servidores públicos estão expostos a outras formas de instabilidade e precarização, tais como: oscilações políticas e de planejamento que geram descontinuidade de projetos em curso; achatamento salarial e perda de direitos trabalhistas; acúmulo de papéis; mudanças na organização do trabalho ou na natureza das tarefas que, por vezes, se chocam com o sentido e as crenças que os trabalhadores construíram em relação ao seu trabalho.

A relação desenvolvida entre os servidores públicos e os usuários está permeada de conflitos. Em situações de insatisfação, por vezes, os usuários direcionam sua ira ao trabalhador que está a sua frente e que representa a instituição prestadora do serviço, transformando os funcionários que trabalham na linha de frente em anteparo para as inoperâncias do sistema.

\section{O setor de transporte urbano}

O aumento dos deslocamentos dos munícipes, tanto em número quanto em distância, e os congestionamentos que eles geram é uma das características das grandes cidades. A Companhia de Engenharia de Tráfego de São Paulo (CET) foi criada com a responsabilidade, entre outras, de operar o sistema viário e de gerenciar e racionalizar o estacionamento rotativo nas ruas da cidade, conhecido como Zona Azul (ZA). Considerando a importância do trânsito para a cidade de São Paulo entenderemos o que torna a CET uma empresa de grande visibilidade e importância.
Apesar de tratar-se de uma sociedade de economia mista vinculada ao município e do contrato de seus trabalhadores ser regido pela CLT, a companhia guarda diversas características de empresa pública, em especial a influência política da administração municipal. Assim, está vulnerável a mudanças e interesses políticos.

Esta pesquisa foi realizada a partir de demanda da CET voltada para o trabalho dos agentes de trânsito, funcionários responsáveis pelo setor da Zona Azul. A empresa identificava uma série de mudanças ocorridas nas atribuições destes trabalhadores acrescida de um processo de envelhecimento e de deterioração da saúde que vinha gerando afastamentos e adoecimentos. O estudo solicitado visava a identificação de situações geradoras de sofrimento patogênico e a proposição de mudanças no trabalho de forma a torná-lo menos agressivo à saúde (LANCMAN et al., 2005).

Em 2004, data do início do trabalho de campo, a ZA passou por um processo de re-estruturação que previa a privatização do setor, a instalação de parquímetros e a transferência de algumas responsabilidades, tais como, a fiscalização e emissão de multas para o setor de operação. Com isso, o cargo de agentes de trânsito seria gradativamente extinto e esses funcionários seriam incorporados à Operação. Os requisitos para a transferência eram possuir o segundo grau completo, carteira de habilitação profissional e não possuir restrição médica que fosse limitante para o exercício do novo papel.

Apesar de a pesquisa ter se iniciado antes dos processos de mudança serem instaurados na companhia, o trabalho de campo ocorreu no contexto onde o papel de fiscalização da ZA estava em processo de extinção. A transferência gradativa já havia alcançado $60 \%$ dos agentes (de um total de 431) e os demais aguardavam uma definição da empresa quanto a prazos e ao destino de cada um. Os $40 \%$ restantes (173 agentes) não puderam ou não se sentiram aptos para a transferência.

Após o término da pesquisa e com a mudança de administração municipal, o processo de extinção da ZA foi interrompido e revertido. Assim, o diagnóstico solicitado terminou por subsidiar a empresa nesta re-estruturação. Gostaríamos de salientar como a realidade e as transformações no trabalho são, por vezes, muito mais rápidas do que o processo dos pesquisadores em apreendê-las.

\section{Sofrimento psíquico no trabalho sob a ótica da psicodinâmica do trabalho}

A psicodinâmica do trabalho (PDT) é uma das 
disciplinas que mais tem se dedicado a compreender os aspectos subjetivos envolvidos no "ato de trabalhar" e as formas de superação que os trabalhadores desenvolvem para fazer frente aos constrangimentos vivenciados no trabalho, preservarem sua saúde e poderem desenvolver suas tarefas a contento.

Várias pesquisas e ações vêm sendo desenvolvidas por Christophe Dejours e sua equipe no Conservatoire des Arts et Metiers na França desde a década de 80 e têm sido largamente divulgadas no Brasil. Entre os aspectos que a PDT busca dar relevo destacamos: os mecanismos de cooperação, a visibilidade e o reconhecimento, a relação prazer e sofrimento, a mobilização da inteligência, da vontade e da motivação e os processos de identificação e de realização de si. Um de seus pressupostos fundamentais defende que o trabalho é um elemento central na construção da saúde e da identidade dos indivíduos e que sua influência transcende o tempo da jornada de trabalho, propriamente dita, e se estende para o tempo do não trabalho (BANDT et al., 1995; DEJOURS, 2004b,c).

Convém aqui aprofundar o conceito de sofrimento e prazer no trabalho proposto pela PDT. O sofrimento no trabalho decorre do confronto do indivíduo com os desafios externos, que lhe obrigam a tomar decisões que põem em cheque suas capacidades, sua formação, seus desejos e seus valores. Esse sofrimento é inerente ao trabalho e pode ser considerado como uma oportunidade de crescimento e de desenvolvimento pessoal. Se o individuo não encontra possibilidades de superação e transformação desse sofrimento em prazer, este se transforma em fonte de sofrimento patológico. Este último ocorre quando os trabalhadores não encontram meios de dar vazão a esse sofrimento, pois a maneira como o trabalho é organizado bloqueia as possibilidades de expressão e de negociação. (DEJOURS et al., 1994 ; DEJOURS, 2003). Assim, o trabalho e as relações que nele se originam nunca podem ser consideradas como um espaço de neutralidade subjetiva ou social.

\section{OBJETIVOS}

Compreender o impacto do conteúdo e da organização do trabalho dos agentes de trânsito nos processos de sofrimento psíquico vivenciados por eles e verificar se estes processos podem ser considerados como fonte de deterioração da saúde e se influenciam o processo de envelhecimento destes trabalhadores.

Trata-se de uma população predominantemente de mulheres (87,6\%), com mais de 40 anos (74\%) e que exercem a função há mais de 10 anos (78\%). Devido a essas características dos trabalhadores é nosso objetivo também compreender a maneira como o trabalho e as suas condições de execução influenciam o processo de envelhecimento e se propiciam eventuais diminuições de certas capacidades e, ainda, como e de que forma o acúmulo de experiência facilita uma reorganização eficiente da maneira de trabalhar.

É nosso objetivo, ainda, compreender se diferentes aspectos relacionados ao tema podem ser aplicados para outros contextos e situações, contribuindo assim para o desenvolvimento teórico do campo da PDT.

\section{MÉTODOS}

O método proposto pela PDT é circunscrito no âmbito da pesquisa-ação onde a investigação pressupõe simultaneamente uma ação transformadora na situação estudada. Neste caso, a ação esperada, é não somente mudanças na situação pesquisada, mas, sobretudo, o engajamento do coletivo dos trabalhadores como coresponsáveis pela ação em si.

Busca-se constituir grupos de expressão com os trabalhadores visando promover reflexões sobre seu processo de trabalho que, contribuam na apreensão da complexidade do ato de trabalhar. Os grupos de reflexão possibilitam a transformação de compreensões individuais em reflexões coletivas sobre o trabalho. Esses grupos permitem também compreender a inteligência desenvolvida no ato de trabalhar e os esforços dos trabalhadores para fazê-lo acontecer apesar dos constrangimentos e dificuldades.

O método preconizado não é uma mera observação ou coleta de dados, os aspectos subjetivos do trabalho são apreendidos a partir de uma discussão realizada num espaço aberto à deliberação através da criação de "espaços públicos". As interpretações e os sentidos para os fatos apresentados não são construídos a partir do ponto de vista externo dos pesquisadores, mas são frutos do sentido construído pelos participantes em relação as situações de trabalho vivenciadas.

As várias etapas que constituem esse método têm sido descritas em diversos trabalhos e podem ser apresentados de forma resumida nas seguintes fases: a) pré-pesquisa: onde se busca criar as condições necessárias para a realização da mesma; b) re-configuração da demanda: fase onde se busca compreender com os participantes a demanda de análise de trabalho deles, aquilo que os mobiliza e os engaja numa busca de inteligibilidade da situação, demanda esta que, em geral, não é a mesma dos gestores; c) apresentação do projeto aos trabalhadores, para que 
estes conheçam os objetivos da pesquisa-ação e possam escolher se querem participar ou não dos grupos; d) restituição e validação: nesta etapa o produto das discussões é apresentado aos participantes sob a forma de relatório para que estes possam, num processo interativo com os pesquisadores, validar / refutar a análise e os resultados apresentados, além de favorecer a re-apropriação e elaboração do material produzido (DEJOURS, 2004a). Após esta etapa, o relatório final é apresentado ao conjunto dos trabalhadores que não participaram diretamente dos grupos e à instituição.

Nesse estudo, foram constituídos dois grupos de reflexão tendo como princípio fundamental o critério do voluntariado: o primeiro foi composto por seis trabalhadores e adotou-se como critério de inclusão agentes que permaneciam na fiscalização do estacionamento rotativo. O segundo foi composto por oito trabalhadores que já haviam sido transferidos para a operação de tráfego. Os dois grupos ocorreram no segundo semestre de 2004 durante o horário de trabalho, ao longo de seis sessões de uma hora e meia de duração, com frequiência semanal. Ao final os relatórios foram validados com os participantes dos grupos. Somente após estas validações, foi apresentado um relatório final.

\section{RESULTADOS}

(Os trechos apresentados em itálico são falas dos trabalhadores retiradas do relatório por eles validado LANCMAN et al., 2005).

O trabalho na ZA sofreu diversas mudanças ao longo dos anos. Algumas tarefas foram incorporadas (vendas de folhas e talões de zona azul, aplicação de multas) e outras deixaram de ser realizadas. Algumas destas mudanças pioraram as condições de trabalho e aumentaram a exposição a riscos, conflitos com os usuários, violência e assaltos.

$\mathrm{O}$ projeto do trabalho não considerou as particularidades das diversas regiões nas quais os agentes trabalham. Por exemplo, a produção é calculada sobre o número de vagas a serem fiscalizadas, sendo que, em algumas regiões há um maior número de garagens e as vagas ficam mais distantes umas das outras, a rotatividade de carros é maior e varia ao longo do dia. Um outro aspecto não apreciado foi a periculosidade de determinadas regiões, a ocupação de vagas da ZA por camelôs e outros tipos de comércio ambulante.

Vários fatores causam constrangimentos físicos, tais como: exposição à chuva, ao frio, ao calor, ao sol, à poluição ambiental, ao ruído, o tempo que permanecem em pé e o peso do material que necessitam carregar (talões e dinheiro).
Entre os constrangimentos psíquicos, destacamos a vulnerabilidade a assaltos, conflitos e agressões, tanto morais, quanto físicas. Por vezes, os agentes envolvem-se em conflitos quando multam algum carro, quando solicitam a colocação do cartão ou, ainda, quando se deparam com irregularidades relacionadas a ZA (controle de vagas por seguranças privados, cambistas, apropriação do espaço público por camelôs e comerciantes).

"Tem que ter jogo de cintura! Com o tempo vamos cansando, a tolerância para lidar com os conflitos de rua vai diminuindo. O desgaste psicológico é muito grande". "Os munícipes descontam seus problemas na ZA". "Se tivesse ido paras as 'vias de fato' no dia seguinte teria que trabalhar do mesmo jeito e na mesma área e ninguém vai querer saber se você está com trauma, com problemas psicológicos".

Em muitas situações o munícipe enfrenta os agentes, principalmente quando este é surpreendido fazendo uma autuação. A ação do agente nesse momento pode apaziguar ou acirrar o conflito e eles estão quase que inexoravelmente sozinhos nessas situações, só podendo recorrer a outros munícipes.

Com a experiência, procuram se mostrar invisíveis, para evitar conflitos ou evitar que eles se exacerbem. Embora discriminem as agressões verbais das físicas e, estas últimas sejam menos freqüentes, o medo, a insegurança, o sentimento de exposição e vulnerabilidade são constantes.

O trabalho de rua só tem um agravante: a população nos vê como pessoas que estão lá para tirar dinheiro, para cobrar mais uma taxa e não como agente que irá democratizar o espaço público"; "Nos vêem como 'puxa saco' do governo. Somos um filtro e tanto na rua". "A população não conhece nosso trabalho, existe uma péssima imagem da ZA". "Nós estamos lá para assustar, o munícipe não respeita o funcionário, respeita o talão”.

As constantes situações de conflitos que vivenciam geram diversos tipos de sofrimento que ocasionam a diminuição da tolerância para lidar com o público, fato que aumenta a vulnerabilidade às agressões. Acreditam que esse processo termina gerando queda no desempenho, perda da arrecadação, absenteísmo e adoecimento. A perda da esperança de ter seu trabalho reconhecido é para eles um forte fator de perda da motivação, o que aumenta o sofrimento e o aparecimento de distúrbios psíquicos. Afinal, o que mobiliza e motiva as pessoas para o trabalho não é somente a remuneração, mas a retribuição simbólica pela contribuição que cada um traz à produção, no caso, o exercício da cidadania através da democratização do espaço público.

$\mathrm{O}$ tempo na ZA é vivenciado de maneira diversa. $\mathrm{O}$ 
passar do dia pode ser relativamente lento e monótono: caminhar pelas ruas, conferir os cartões, vendê-los, multar. Eventualmente dão alguma orientação, interagem com o dono do carro ou com algum outro transeunte. Há, no entanto, momentos de conflito que geram ansiedade, quando se deparam com problemas. "Tem o desgaste mental, o estresse que vai aparecer também na vida pessoal. Tem dias em que vivemos várias situações muito difíceis. Fico com medo".

Há uma grande ambivalência entre a construção do papel social e da identidade profissional, da importância que eles atribuem ao seu trabalho, da contribuição que acreditam trazer para a cidade, em contraste com as agressões que recebem dos munícipes, o descaso que atribuem à empresa em relação aos assaltos e às transgressões e pelas diversas pessoas que "privatizaram" o espaço público e que acabam competindo com o trabalho deles.

As mudanças introduzidas no trabalho da ZA não levaram em conta o envelhecimento dos agentes. A idade provoca diminuição da capacidade para esforços físicos intensos, diminuição da mobilidade articular; fragilização do sistema de equilibro aumentando a freqüência de acidentes por quedas. Ocorre ainda, a diminuição de duas importantes modalidades sensoriais: a visão e a audição o que é compensado pelo conhecimento e a inteligência desenvolvidos no trabalho (LAVILLE; VOLKOFF, 2004). Diversas mudanças implantadas, sobretudo a tentativa frustrada de privatização, geraram grande instabilidade e alteraram percursos profissionais. A instabilidade e a incerteza quando se estendem por um tempo elevado, podem comprometer a consolidação da experiência, em particular entre os mais idosos. "Houve grande envelhecimento humano. Não teve cuidado preventivo e sequer avaliação dos funcionários ao longo dos tempos. Nem avaliação física, muito menos psíquica"; "Ficamos no aguardo do derradeiro fim. É muito doloroso"; "Estamos na incerteza como se estivéssemos num paredão, aguardando como será o final".

\section{DISCUSSÃO}

O trabalho e o reconhecimento pelo esforço para fazêlo acontecer é um dos principais alicerces para a construção da saúde mental, caso contrário pode ser desencadeado um processo de elevado nível de sofrimento. A vulnerabilidade gerada no trabalho e o descaso da empresa em protegê-los configura-se como um ataque ao equilíbrio sofrimento/adoecimento gerando absenteísmo, adoecimentos, licenças e um maior processo de desgaste no trabalho.
$\mathrm{O}$ trabalho na rua requer inteligência para enfrentar várias situações que se apresentam no cotidiano do trabalho. Relatam, como exemplo, a habilidade em detectar fraudes no cartão, o jogo de cintura para lidar com o munícipe, o conhecimento da área em que trabalham e uma maior facilidade em lidar com as adversidades vivenciadas. Acreditam que o desenvolvimento desta astúcia lhes deu, também, maiores recursos para lidar com seus problemas cotidianos, tanto no trabalho, quanto na sua vida pessoal e familiar.

A detecção de fraudes e adulteração de cartões aparece como um fator importante, principalmente porque descobrilas é sinal de competência, de sabedoria profissional. A questão não está restrita a multar ou denunciar o fraudador, mas sim, ao reforço da identidade profissional, da competência. Também é uma atitude ética, de fazer valer o direito de todos, garantindo a socialização do espaço público.

Ser um agente público, cuidar do uso democrático do espaço público é construir relações com os munícipes. Tornam-se conhecidos pelos moradores, pelos comerciantes, criam uma rede que os ajuda a integrarem a comunidade, a cultivarem a identidade de serem "agentes comunitários" e enriquece o seu trabalho.

Ao longo desta pesquisa pudemos revelar o quanto a organização e as características do trabalho podem estar levando os agentes a um processo de sofrimento e desgaste psíquico que prevalecem sobre o envelhecimento em si. Nossos achados vêm ao encontro de outras pesquisas realizadas sobre a relação entre sofrimento psíquico, deterioração da saúde e envelhecimento no trabalho.

O trabalhador ao longo da sua vida profissional desenvolve habilidades e formas de preservar seu desempenho e sua saúde para compensar o seu processo de envelhecimento. Os trabalhadores desenvolvem estratégias individuais e coletivas de preservação e de construção da sua saúde e da sua segurança no trabalho, acumulam experiências e um conhecimento de como agir nestas situações. - adaptação ao modo operatório, estratégias de antecipação, de buscar cooperação e de divisão do trabalho.

Observamos relações complexas entre, de um lado, certas características do trabalho e as representações que os indivíduos fazem de suas capacidades de responder às exigências e, de outro, aspectos psíquicos que, apesar de não serem necessariamente um caráter patológico, podem ser considerados como perturbações da saúde mental e estão relacionados a diversas formas de sentimento de impotência, falta de confiança em si e sentimentos de perda da capacidade de fazer frente aos constrangimentos impostos pelo trabalho. A exposição prolongada a estas 
condições pode gerar situações duradouras de perda de iniciativa e de passividade, por vezes, patogênicas para os trabalhadores e prejudiciais para a empresa, principalmente quando a eficácia do trabalho requer um engajamento ativo. As percepções negativas da sua capacidade de avaliar uma situação podem ter reflexos sobre a mobilização de outros recursos igualmente importantes no exercício de atividades cotidianas de trabalho e em particular de recursos cognitivos
(MARQUIÉ et al., 2001).

O trabalho é reconhecido como um local privilegiado de integração social. Ele permite partilhar experiências com os outros e se implicar em atividades que ultrapassam o interesse individual. $\mathrm{O}$ trabalho também permite adquirir um status, uma identidade social, participar de um número maior de redes sociais, de grupos que multiplicam as interações entre os indivíduos.

LANCMAN, S.; SZNELWAR, L. I.; JARDIM, T. A. Psychic suffering and ageing at work: a study with transit agents. Rev. Ter. Ocup. Univ. São Paulo, v. 17, n. 3, p. 129-136, set./dez., 2006.

\begin{abstract}
From a study with transit agents we seek to discuss the relationships between work and mental health and their implications on ageing processes. We aim to understand the generating processes of psychic suffering, their reflexes in life and health, in the development of the work and their relationships. Based on theoretical and methodological principals of the work psychodynamics we proposed workers reflection groups with transit agents that has the street as a work environment. Related to a request linked to signs of health deterioration and increase of absenteeism we've asked if psychic suffering experienced along the years reduces the work capacity to deal with the constraints linked to the work generating loss of tolerance to deal with the public, fact that could increases the vulnerability to aggressions and conflicts.
\end{abstract}

KEY WORDS: Mental health. Work/psychology. Aging. Stress psychological. Working environment/ adverse effects.

\title{
REFERÊNCIAS
}

BERTIN, C.; DERRIENNIC, F. Sentiment de lassitude, âge et conditions de travail. In: Travail, santé, viellissement, relatins et évolutions. Paris: Octares Editions, 2001. Collection colloques.

BANDT, J.; DEJOURS, C.; DUBAR, C. La France malade du travail. Paris: Bayard, 1995.

DEJOURS, C.; ABDOUCHELI, E.; CHRISTIAN, J. Psicodinâmica do trabalho: contribuição da escola dejouriana à análise da relação prazer, sofrimento e trabalho. São Paulo: Atlas, 1994.

DEJOURS, C. Novas formas de organização do trabalho e lesões por esforços repetitivos (LER): abordagem através da psicodinâmica do trabalho. In: SZELWAR, L.; ZIDAN, L. (Orgs.). $O$ trabalho humano com sistemas informatizados no setor de serviços. São Paulo: Plêiade, 2000. p. 37-44.

DEJOURS, C. L'évaluation du travail à l'épreuve du réel. Critiques des fondements de l'evaluation. Paris: INRA, 2003.

DEJOURS, C. A metodologia em psicopatologia do trabalho. In: LANCMAN, S.; SZNELWAR, L. (Orgs.). Christophe Dejours: da psicopatologia à psicodinâmica do trabalho. Brasília: Paralelo15/ FIOCRUZ, 2004a. p. 105-26.
DEJOURS, C. Inteligência prática e sabedoria prática: duas dimensões desconhecidas do trabalho. In: LANCMAN, S.; SZNELWAR, L. (Orgs.). Christophe Dejours: da psicopatologia à psicodinâmica do trabalho. Brasília: Paralelo15/FIOCRUZ, 2004b. p. 277-99.

DEJOURS, C. Patologia da comunicação. Situação de trabalho e espaço público: a geração de combustível com energia nuclear. In: LANCMAN, S.; SZNELWAR, L. (Orgs.) Christophe Dejours: da psicopatologia à psicodinâmica do trabalho. Brasília: Paralelo15/ FIOCRUZ, 2004c. p. 243-76.

GOMEZ, C. M.; THEDIM-COSTA, S. M. F. Precarização do trabalho e desproteção social: desafios para a saúde coletiva. Ciên. Saúde Coletiva, Rio de Janeiro, v. 4/2, p. 411-422, 1999.

LANCMAN, S.; SZNELWAR, L.; GONÇALVES, R.; JARDIM, T. A. Sofrimento psíquico e envelhecimento no trabalho: um estudo com agentes de trânsito na Companhia de Engenharia de Tráfego na cidade de São Paulo: contribuições da terapia ocupacional na prevenção de adoecimentos, afastamentos e aposentadoria precoce. Relatório de pesquisa (apoio CNPq); 2005.

LAVILLE, A.; VOLKOFF, S. Vieillissement et travail. In: 
LANCMAN, S. et al. Sofrimento psíquico e envelhecimento no trabalho. Rev. Ter. Ocup. Univ. São Paulo, v. 17, n. 3, p. 129-136, set./dez., 2006.

FALZON, P. Ergonomie. Paris: Editions Presses Universitaire de France, 2004

MARQUIÉ, J-C.; NIEZBORALA, M.; DELGOULET, C. Quelques composantes psychiques et cognitives de la relation âge, travail, santé. In: Travail, santé, viellissement, relatins et évolutions. Paris: Octares Editions, 2001. Collection colloques.

MOLINIER, P. Psychodynamique du travail et identité sexuelle. 1995. Thése [doctorat en Psychologie]. Paris (França): Conservatoire National des Arts et Metiers, 1995.

SALVADOR, E.; BOSCHETTI, I. (Dês)regulamentação dos direitos previdenciários e (dês)estruturação do mercado de trabalho.

Recebido para publicação: Set./2006

Aceito para publicação: Out./2006
In: FERREIRA, M. C.; ROSSO, S. D. (Orgs.). A regulação social do trabalho. Brasília: Paralelo 15, 2003.

SENNETT, R. A corrosão do caráter. Rio de Janeiro: Record, 1999.

VEZINA, M.; DERRIENNIC, C.; MONFORT, C. Tension au travail et atteintes à la santé mentale: l'éclairage de l'ênquete. In: Travail, santé, viellissement, relatins et évolution. Paris: Octares Editions, 2001. Collection colloques.

VOLKOFF, S.; LAVILLE, A. Le vieillissement au travail. In: KERGOAT, K.; BOUTET, J.; JACOT, H.; LINHART, D. Le monde du travail. Paris: Editions La Découverte, 1998. 